Research Article

\title{
Molecular Analysis of Spinal Muscular Atrophy: A genotyping protocol based on $\operatorname{TaqMan}^{\circledR}$ real-time PCR
}

\author{
Fernanda Marques de Souza Godinho ${ }^{1,2}$, Hugo Bock ${ }^{1,2}$, Tailise Conte Gheno ${ }^{1,3}$ \\ and Maria Luiza Saraiva-Pereira ${ }^{1,2,3,4}$ \\ ${ }^{1}$ Laboratório de Identificação Genética, Centro de Pesquisa Experimental e Serviço de Genética Médica, \\ Hospital de Clínicas de Porto Alegre, RS, Brazil. \\ ${ }^{2}$ Programa de Pós-Graduação em Bioquímica, Universidade Federal do Rio Grande do Sul, \\ Porto Alegre, RS, Brazil. \\ ${ }^{3}$ Programa de Pós-Graduação em Genética e Biologia Molecular, \\ Universidade Federal do Rio Grande do Sul, \\ Porto Alegre, RS, Brazil. \\ ${ }^{4}$ Departamento de Bioquímica, Universidade Federal do Rio Grande do Sul, Porto Alegre, RS, Brazil.
}

\begin{abstract}
Spinal muscular atrophy (SMA) is an autosomal recessive inherited disorder caused by alterations in the survival motor neuron I (SMN1) gene. SMA patients are classified as type I-IV based on severity of symptoms and age of onset. About 95\% of SMA cases are caused by the homozygous absence of SMN1 due to gene deletion or conversion into SMN2. PCR-based methods have been widely used in genetic testing for SMA. In this work, we introduce a new approach based on TaqMan real-time PCR for research and diagnostic settings. DNA samples from 100 individuals with clinical signs and symptoms suggestive of SMA were analyzed. Mutant DNA samples as well as controls were confirmed by DNA sequencing. We detected 58 SMA cases (58.0\%) by showing deletion of SMN1 exon 7. Considering clinical information available from 56 of them, the patient distribution was 26 (46.4\%) SMA type I, 16 (28.6\%) SMA type II and 14 (25.0\%) SMA type III. Results generated by the new method was confirmed by PCR-RFLP and by DNA sequencing when required. In conclusion, a protocol based on real-time PCR was shown to be effective and specific for molecular analysis of SMA patients.
\end{abstract}

Keywords: SMA, SMN1 gene, gene conversion, molecular analysis.

\section{Introduction}

Spinal muscular atrophy (SMA) is a genetic disorder characterized by symmetric proximal muscle weakness due to degeneration of the anterior horn cells of the spinal cord. Based on the severity of symptoms and age of onset, SMA is divided into four clinical types (Zerres and RudnikSchoneborn, 1995). Type I [Werdnig-Hoffman disease, Online Mendelian Inheritance in Man (OMIM) 253300] is the most severe form, characterized by muscle weakness and hypotonia within first days/months of life, resulting in death before the age of two. Type II (OMIM 253550) is characterized by proximal muscle weakness with onset between six to 12 months after birth, inability to walk and variable survival. Type III (Kugelberg-Welander disease,

Send correspondence to Maria Luiza Saraiva-Pereira. Serviço de Genética Médica, Hospital de Clínicas de Porto Alegre, Rua Ramiro Barcelos 2350, 90035-903 Porto Alegre, RS, Brazil. E-mail: mlpereira@hcpa.ufrgs.br.
OMIM 253400) is marked by proximal muscle weakness after the age of 18 months, with survival to adulthood. Type IV (OMIM 271150) shows similar findings to those described for SMA III, except that the onset of muscle weakness usually only occurs in the second or third decade of life. SMA is an autosomal recessive disease with a prevalence of 1 in 10,000 and a carrier incidence of 1 in 50 (Ogino and Wilson, 2002).

The genomic locus of the disease is located at 5 q11.2-q13.3 within a region characterized by a large inverted duplication of a $500 \mathrm{~kb}$ element (Lefebvre et al., 1995). Included in this region is the SMA-determining gene, the survival motor neuron gene $(S M N)$, which is also duplicated and both copies expressed (Burglen et al., 1996). Both $S M N$ genes are highly homologous and differ by few nucleotides changes within their 3' regions. These differences in exon 7 and exon 8 are used to distinguish the telomeric (SMN1, OMIM 600354) from the centromeric $S M N$ copy (SMN2, OMIM 601627) in DNA analysis 
(Wirth, 2000). Despite the high similarity between these two genes, SMN1 protein is the only one that is required for the survival of motor neurons. In about $95 \%$ of the patients, the pathogenic mutation consists of the homozygous functional absence of exon 7 and 8, or only exon 7, of SMN1 due to deletion or conversion to $S M N 2$, respectively (Cobben et al., 1995; Hahnen et al., 1995; Lefebvre et al., 1995; Velasco et al., 1996; Simard et al., 1997). The remaining cases are compound heterozygotes for a deletion/conversion of one SMN1 allele and a small intragenic mutation of the other allele, or more rarely, intragenic mutations in both alleles (Wirth et al., 1999). SMN2 is present in all patients but is unable to fully compensate for loss of SMN1.

A transition $840 \mathrm{C}>\mathrm{T}$ in exon 7 leads to exon skipping (Cartegni et al., 2006). As a result, most transcripts from SMN2 lack exon 7, and the resultant truncated protein appears biochemically unstable and is rapidly degraded in vivo (Chang et al., 2004; Vitte et al., 2007). SMN2 is unrelated to the disease, and deletion of both SMN2 genes occurs in about $5 \%-10 \%$ of unaffected individuals (Gerard et al., 2000). Nevertheless, SMN2 is considered a diseasemodifying gene because its copy number is related to disease severity and survival of affected patients (McAndrew et al., 1997; Wirth et al., 1999; Feldkotter et al., 2002).

Direct DNA testing for detecting homozygous SMN1 loss is an effective method for molecular diagnosis of SMA patients and has been widely used for confirmation of clinical diagnosis. Almost all genetic tests for SMA are designed to identify the homozygous absence of SMN1 exon 7 due to the fact that the vast majority of symptomatic SMA patients have homozygous SMN1 exon 7 deletion/conversion. In order to detect alteration in the SMN1 gene, the polymerase chain reaction-restriction fragment length polymorphism (PCR-RFLP) assay remains a commonly used method along with modern approaches (van der Steege et al., 1995). However, a number of other methodologies have been introduced to date, mainly quantitative assays based on different strategies and focusing dosage analysis on hemizygous SMN1 deletions (Wirth et al., 1999; Scheffer et al., 2000; Xu et al., 2003; Gómez-Curet et al., 2007; Passon et al., 2009; Maranda et al., 2012), considering that gene dosage is essential for carrier detection.

We have previously used the PCR-RFLP test in our laboratory, which is routinely performed to identify SMA cases. In this present work, we describe a protocol using TaqMan $^{\circledR}$ real-time PCR technology for detecting SMA patients that are homozygous for SMN1 exon 7 deletion. This method was based upon the fact that SMN1 exon 7 differs from $S M N 2$ exon 7 by a single nucleotide change, and specific probes will only detect the SMN1 or SMN2 sequence. We applied both methods in a cohort of individuals with clinical signs and symptoms of SMA, aiming to identify new cases and the applicability of a new method in research and diagnostic settings.

\section{Material and Methods}

The study comprised 100 unrelated individuals that were referred to the Medical Genetics Service of Hospital de Clínicas de Porto Alegre (HCPA) for genetic investigation due to clinical signs and symptoms of SMA. The great majority ( 80 cases) were from the State of Rio Grande do Sul, Brazil). This study was approved by the local Ethics Committee in Porto Alegre.

Genomic DNA from peripheral blood of individuals was isolated by a standard procedure (Miller et al., 1988). DNA quantity was determined by Quant-iT dsDNA BR Assay kit (Invitrogen, Carlsbad, USA) and samples were diluted to $50 \mathrm{ng} / \mu \mathrm{L}$ and to $10 \mathrm{ng} / \mu \mathrm{L}$ in water. Negative and positive control samples were also included in the analyses.

Presence or deletion of exon 7 and exon 8 SMN1 and SMN2 genes were detected primarily by PCR-RFLP analysis as previously described (van der Steege et al., 1995). The PCR amplification of exon 7 and exon 8 of the SMN genes was carried out in a total volume of $25 \mu \mathrm{L}$ with the following final concentrations: $200 \mu \mathrm{M}$ of each dNTP, $20 \mathrm{mM}$ Tris- $\mathrm{HCl}$ ( $\mathrm{pH} \mathrm{8.4),} 50 \mathrm{mM} \mathrm{KCl}, 800 \mathrm{nM}$ of each primer, $1.5 \mathrm{mM} \mathrm{MgCl} 2,1.25 \mathrm{U}$ Taq DNA polymerase, $100 \mathrm{ng}$ of genomic DNA, and 4\% (v/v) of dimethylsulfoxide (DMSO) for exon 8 only. Amplification was performed as follows: an initial denaturation at $94{ }^{\circ} \mathrm{C}$ for $10 \mathrm{~min}$, followed by 32 cycles of denaturation at $94^{\circ} \mathrm{C}$ for $1 \mathrm{~min}$, annealing at $57^{\circ} \mathrm{C}$ (exon 7) $/ 58^{\circ} \mathrm{C}$ (exon 8) for $1 \mathrm{~min}$, and extension at $72^{\circ} \mathrm{C}$ for $1 \mathrm{~min}$, followed by a final extension step at $72{ }^{\circ} \mathrm{C}$ for $10 \mathrm{~min}$. Exon 7 was amplified with a forward intron 6 primer R111 (Lefebvre et al., 1995) and a mismatched reverse exon 7 primer X7-Dra (van der Steege et al., 1995) that creates a DraI restriction site in the SMN2 product. Exon 8 was amplified with forward primer 541C960 and reverse primer 541C1120 (Lefebvre et al., 1995). Digestion reactions were done using 10 units of restriction enzymes, DraI for exon 7 and DdeI for exon 8, and kept at $37^{\circ} \mathrm{C}$ overnight. Digested PCR products were analyzed by electrophoresis in a $3 \%(\mathrm{w} / \mathrm{v})$ agarose gel and visualized by ethidium bromide staining under UV light.

Probes and primers for real-time PCR were designed using the Primer Express ${ }^{\circledR}$ Software v.3.0 (Applied Biosystems, Foster City, USA). Probes were specific for the SMN1 and SMN2 copies at base position 6 in exon 7. SMN1 and SMN2 probes were labeled with $6 \mathrm{FAM}^{\mathrm{TM}}$ and $\mathrm{NED}^{\mathrm{TM}}$ fluorescin dye at the 5, end respectively and contained a minor groove binder (MGB) and a nonfluorescent quencher (NFQ) at the 3' end (Table 1).

PCR was carried out in a 7500 Fast Real-Time PCR System (Applied Biosystems, Foster City, USA) using a 96-well format. PCR amplifications for detecting SMN1 exon 7 was performed in a total volume of $12 \mu \mathrm{L}$, containing $6 \mu \mathrm{L}$ of TaqMan ${ }^{\circledR}$ Genotyping PCR Master Mix (Applied Biosystems, Foster City, USA), $900 \mathrm{nM}$ of each primer, $250 \mathrm{nM}$ of SMN1ex7 probe (SMN1 gene) or 
Table 1 - Primers and probes for detecting SMN1 and SMN2 genes using $\operatorname{TaqMan}^{\circledR}$ analysis.

\begin{tabular}{ll}
\hline Component & Sequence $\left(5^{\prime}>3^{\prime}\right)$ \\
\hline Primers & \\
SMNex7-F & AAT GCT TTT TAA CAT CCA TAT AAA GC \\
SMNex7-R & CTT AAT TTA AGG AAT GTG AGC ACC \\
Probes & \\
SMN1ex7 & 6FAM-CAG GGT TTC* AGA CAA A-MGB-NFQ \\
SMN2ex7-anti & NED-ATT TTG TCT A*AA ACC C-MGB-NFQ \\
\hline
\end{tabular}

*Asterisks denote specific nucleotides for SMN1 or SMN2 gene copies.

SMN2ex7-anti probe (SMN2 gene), $0.3 \mu \mathrm{L}$ of eukaryotic 18S rRNA TaqMan ${ }^{\circledR}$ Endogenous Control $\left(\mathrm{VIC}^{\circledR} / \mathrm{MGB}\right.$ Probe, Primer Limited; Applied Biosystems, Foster City, USA) and $20 \mathrm{ng}$ of genomic DNA. The following amplification protocol was used: activation of AmpErase ${ }^{\circledR}$ UNG function at $50{ }^{\circ} \mathrm{C}$ for $2 \mathrm{~min}$, AmpliTaq Gold ${ }^{\mathbb{B}}$ activation at $95^{\circ} \mathrm{C}$ for $10 \mathrm{~min}$, followed by 40 cycles of denaturation at $95^{\circ} \mathrm{C}$ for $15 \mathrm{~s}$, and annealing/extension at $62{ }^{\circ} \mathrm{C}(S M N 1$ exon 7) or $60^{\circ} \mathrm{C}(S M N 2$ exon 7) for $1 \mathrm{~min}$.

To estimate the influence of cross hybridizations between the SMN1 and SMN2 genes and respective probes, DNA samples from patients homozygous for $S M N 1$ or SMN2 deletions were analyzed using both probes. PCR efficiency was monitored by adding specific primers for amplification of the eukaryotic 18S rRNA gene in each well as endogenous control. Data generated were analyzed using the Sequence Detection Software v.1.4.0 (Applied Biosystems, Foster City, USA).

Direct DNA sequencing was performed to confirm the genotype of three DNA samples as follows: one sample carrying both genes, one sample lacking the $S M N 2$ gene and a sample lacking the SMN1 gene (indicative of SMA). Direct DNA sequencing was also used to confirm cases of gene conversion.

For DNA sequencing, exon 7 and exon 8 of the $S M N$ genes were amplified using the same primers employed in PCR-RFLP analysis. Amplification conditions were similar except for primer concentration (600 $\mathrm{nM}$ of each primer) and amount of DNA (50 ng). After PCR amplification, samples were purified using $2.5 \mathrm{U}$ of Exonuclease I (USB Corporation, Cleveland, USA) and $0.25 \mathrm{U}$ of Shrimp Alkaline Phosphatase (USB Corporation, Cleveland, USA). The reaction mixtures were kept at $37{ }^{\circ} \mathrm{C}$ for $30 \mathrm{~min}$ followed by $15 \mathrm{~min}$ at $80^{\circ} \mathrm{C}$. Purified amplicons were sequenced using the BigDye ${ }^{\circledR}$ Terminator v.3.1 Cycle Sequencing kit (Applied Biosystems, Foster City, USA), according to the manufacturer's recommendations. Sequencing products were purified by ethanol/ethylenediamine tetraacetic acid (EDTA) precipitation, and resuspended in formamide solution. Fragments were then resolved by capillary electrophoresis in the ABI Prism 3130xl Genetic Analyzer (Applied Biosystems, Foster City, USA). Se- quencing data were analyzed using Sequencing Analysis Software v.5.3.1 (Applied Biosystems, Foster City, USA).

\section{Results}

Within the population of 100 individuals we detected 58 SMA cases $(58.0 \%)$ through both methodologies, confirming the lack of $S M N 1$ exon 7 in these patients. We also evaluated exon 8 of the $S M N$ genes by PCR-RFLP analysis, and the presence of SMN1 exon 8 was detected in 8 out of these 58 confirmed SMA patients (13.8\%), indicating the occurrence of gene conversion events in these patients. One of these patients showed a homozygous deletion of SMN2 exon 8 , probably due to the fact that only one allele with this region of SMN2 was originally present, which was converted to SMN1 exon 8, as stated above. Additionally, we found 5 individuals with a complete deletion of the SMN2 gene within the remaining 42 individuals of the studied population. Figure 1 represents results obtained with this assay.

Clinical information available from SMA confirmed patients permitted to define the clinical type for 56 of them, according to the revised diagnostic criteria for SMA suggested by the European Neuro Muscular Centre (ENMC) (Zerres and Rudnik-Schoneborn, 1995). This is based on the age of onset and achievable motor milestones. Patient distribution was 26 (46.4\%) with SMA type I, 16 (28.6\%) with SMA type II and 14 (25.0\%) with SMA type III.

The proposed protocol based on TaqMan ${ }^{\mathbb{B}}$ real-time PCR analysis was introduced and amplification conditions were able to eliminate cross hybridizations. We have also

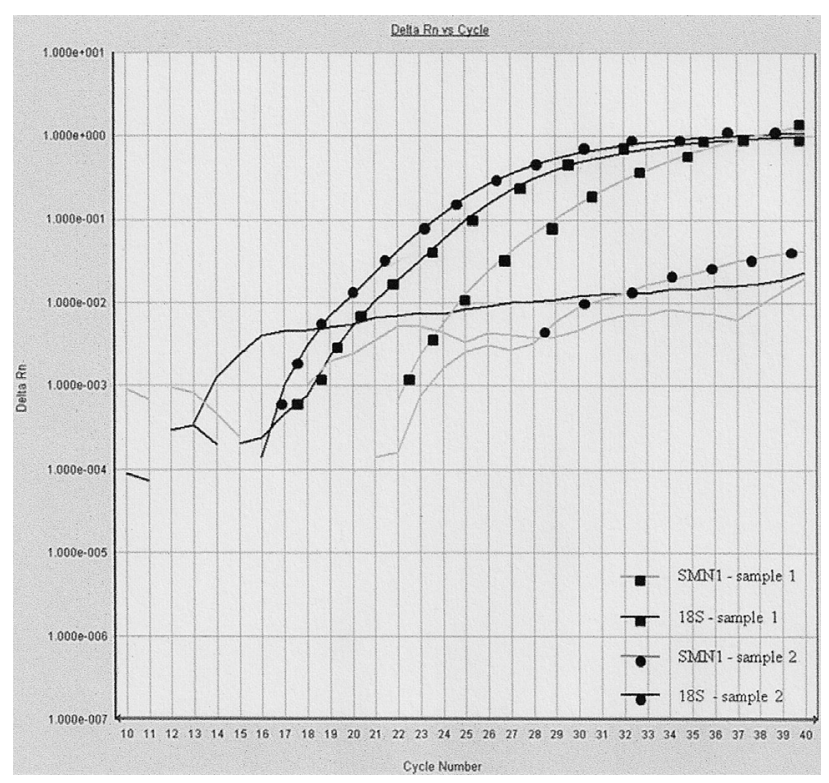

Figure 1 - TaqMan ${ }^{\circledR}$ assay for the $S M N 1$ gene. Sample 1 is DNA from an individual with the $S M N 1$ gene, showing both $S M N 1$ gene and eukaryotic 18S rRNA gene amplification. Sample 2 is DNA from a patient with a deletion of SMN1 (indicative of SMA) showing only amplification of the eukaryotic 18S rRNA gene. Remaining lines with no amplification represent the negative control. 
ruled out false positive results by simultaneously amplifying an endogenous control gene. Results from this new approach were all confirmed by the well established genotyping methodology (PCR-RFLP analysis). All negative and positive controls were submitted to direct DNA sequencing, the gold standard in sequence validation, to confirm genotypes (data not shown).

Both methodologies were accurate and reproducible for detecting the homozygous loss of the SMN1 gene, corroborating molecular detection for a great majority of SMA patients. Once optimized, the $\mathrm{TaqMan}^{\circledR}$ real-time PCR analysis was faster due to fewer manipulation steps. In addition, we were also able to reduce the amount of DNA required for analysis due to the higher sensitivity of this technology.

\section{Discussion}

Molecular analysis to detect the lack of SMN1 has been proven to be a specific tool for the diagnosis of SMA patients. Besides PCR-RFLP analysis, more sophisticated approaches, such as multiplex ligation-dependent probe amplification (MLPA) and methodologies based on capillary electrophoresis, have also been applied in recent years to determine SMN1 and SMN2 copy number (Passon et al., 2010; Wang et al., 2010). These methodologies are very powerful and generate highly informative results. However, they require sophisticated equipment and highly skilled personnel, therefore the need for an alternative for use in a routine diagnostic laboratory.

We present herein a protocol designed to improve molecular analysis of SMA. When compared to classic PCR-RFLP analysis, we found that the TaqMan ${ }^{\circledR}$ real-time PCR-based assay produced results within a considerably shorter period of time, with fewer manipulation steps and requiring smaller amounts of DNA than the PCR-RFLP method. These aspects become particularly relevant in the diagnosis of patients with SMA type I, for which onset is at an early age and disease progression is fast and devastating. These severe cases are in general presented in newborns where sample collection can be difficult and a result is essential for taking appropriate therapeutic measures. The protocol can be also adapted for the quantification of SMN1 and SMN2 copy number. This adapted protocol should be also useful for the detection of heterozygotes.

In the study cohort, $42.0 \%$ of the cases were not homozygous for SMN1 exon 7 deletion. These results were confirmed by both methodologies. It remains possible that some of these patients may carry intragenic mutations, as previously reported to occur in around $4 \%$ of the cases in other studies (Wirth, 2000; Zapletalova et al., 2007). Available clinical data showed a high frequency of SMA type I patients $(46.4 \%)$, which is similar to other studies with SMA patients (Velasco et al., 1996; Wirth, 2000). Gene conversion was also identified and presented in $13.8 \%$ of the confirmed patients. This frequency is comparable to data from Hahnen et al. (1995) who found a frequency of $12 \%$ for conversion events in SMA patients. In our cohort, such conversion events occurred in patients with milder SMA (SMA type II and type III cases). They were present in $28.6 \%$ of the SMA type III patients and in $18.8 \%$ of the SMA type II ones. These results corroborate the hypothesis that an increase in SMN2 gene copy number would be responsible for the less severe SMA phenotypes (Wirth et al., 2006; Watihayati et al., 2009). Gene conversion was only detected in a single SMA type I patient, but this patient was also homozygous for a SMN2 exon 8 deletion, which may be the primary cause of a more severe phenotype. Another interesting finding was that five individuals were found to be homozygous for a $S M N 2$ gene deletion. It remains to be shown whether the phenotype presented by these individuals was caused by a different clinical condition or by mutations in SMN1 other than the exon 7 deletion.

In conclusion, a protocol based on real-time PCR was shown to be effective and specific for detecting SMA patients. Therefore, this method should become an additional option for SMA genotyping for research and/or diagnosis.

\section{Acknowledgments}

The authors are grateful to the patients and their families for contributing to this study. We would also like to thank the medical doctors from the Medical Genetics Service of Hospital de Clínicas de Porto Alegre who referred patients and provided clinical information. This research was supported by the following Brazilian Funding Agencies: CNPq, CAPES, FAPERGS and FIPE-HCPA.

\section{References}

Burglen L, Lefebvre S, Clermont O, Burlet P, Viollet L, Cruaud C, Munnich A and Melki J (1996) Structure and organization of the human survival motor neurone (SMN) gene. Genomics $32: 479-482$

Cartegni L, Hastings ML, Calarco JA, de Stanchina E and Krainer AR (2006) Determinants of exon 7 splicing in the spinal muscular atrophy genes, SMN1 and SMN2. Am J Hum Genet 78:63-77.

Chang HC, Hung WC, Chuang YJ and Jong YJ (2004) Degradation of survival motor neuron (SMN) protein is mediated via the ubiquitin/proteasome pathway. Neurochem Int 45:1107-1112.

Cobben JM, van der Steege G, Grootscholten P, de Visser M, Scheffer H and Buys CH (1995) Deletions of the survival motor neuron gene in unaffected siblings of patients with spinal muscular atrophy. Am J Hum Genet 57:805-808.

Feldkotter M, Schwarzer V, Wirth R, Wienker TF and Wirth B (2002) Quantitative analyses of SMN1 and SMN2 based on real-time lightCycler PCR: Fast and highly reliable carrier testing and prediction of severity of spinal muscular atrophy. Am J Hum Genet 70:358-368.

Gerard B, Ginet N, Matthijs G, Evrard P, Baumann C, Da Silva F, Gerard-Blanluet M, Mayer M, Grandchamp B and Elion J (2000) Genotype determination at the survival motor neuron 
locus in a normal population and SMA carriers using competitive PCR and primer extension. Hum Mutat 16:253-263.

Gómez-Curet I, Robinson KG, Funanage VL, Crawford TO, Scavina $\mathrm{M}$ and Wang W (2007) Robust quantification of the SMN gene copy number by real-time TaqMan PCR. Neurogenetics 8:271-278.

Hahnen E, Forkert R, Marke C, Rudnik-Schoneborn S, Schonling J, Zerres K and Wirth B (1995) Molecular analysis of candidate genes on chromosome $5 \mathrm{q} 13$ in autosomal recessive spinal muscular atrophy: Evidence of homozygous deletions of the SMN gene in unaffected individuals. Hum Mol Genet 4:1927-1933.

Lefebvre S, Burglen L, Reboullet S, Clermont O, Burlet P, Viollet L, Benichou B, Cruaud C, Millasseau P, Zeviani M, et al. (1995) Identification and characterization of a spinal muscular atrophy-determining gene. Cell 80:155-165.

Maranda B, Fan L, Soucy JF, Simard L and Mitchell GA (2012) Spinal muscular atrophy: Clinical validation of a single-tube multiplex real time PCR assay for determination of SMN1 and SMN2 copy numbers. Clin Biochem 45:88-91.

McAndrew PE, Parsons DW, Simard LR, Rochette C, Ray PN, Mendell JR, Prior TW and Burghes AH (1997) Identification of proximal spinal muscular atrophy carriers and patients by analysis of SMNT and SMNC gene copy number. Am J Hum Genet 60:1411-1422.

Miller SA, Dykes DD and Polesky HF (1988) A simple salting out procedure for extracting DNA from human nucleated cells. Nucleic Acids Res 16:1215.

Ogino S and Wilson RB (2002) Genetic testing and risk assessment for spinal muscular atrophy (SMA). Hum Genet 111:477-500.

Passon N, Dubsku de Wittenau G, Jurman I, Radovic S, Bregant E, Molinis C, Damante G and Lonigro IR (2010) Quick MLPA test for quantification of SMN1 and SMN2 copy numbers. Mol Cell Probes 24:310-314.

Passon N, Pozzo F, Molinis C, Bregant E, Gellera C, Damante G and Lonigro RI (2009) A simple multiplex real-time PCR methodology for the SMN1 gene copy number quantification. Genet Test Mol Biomarkers 13:37-42.

Scheffer H, Cobben JM, Mensink RG, Stulp RP, van der Steege G and Buys CH (2000) SMA carrier testing: Validation of hemizygous SMN exon 7 deletion test for the identification of proximal spinal muscular atrophy carriers and patients with a single allele deletion. Eur J Hum Genet 8:79-86.

Simard LR, Rochette C, Semionov A, Morgan K and Vanasse M (1997) SMN(T) and NAIP mutations in Canadian families with spinal muscular atrophy (SMA): Genotype/phenotype correlations with disease severity. Am J Med Genet 72:5158.

van der Steege G, Grootscholten PM, van der Vlies P, Draaijers TG, Osinga J, Cobben JM, Scheffer H and Buys CH (1995)
PCR-based DNA test to confirm clinical diagnosis of autosomal recessive spinal muscular atrophy. Lancet 345:985986.

Velasco E, Valero C, Valero A, Moreno F and Hernandez-Chico C (1996) Molecular analysis of the SMN and NAIP genes in Spanish spinal muscular atrophy (SMA) families and correlation between number of copies of CBCD541 and SMA phenotype. Hum Mol Genet 5:257-263.

Vitte J, Fassier C, Tiziano FD, Dalard C, Soave S, Roblot N, Brahe C, Saugier-Veber P, Bonnefont JP and Melki J (2007) Refined characterization of the expression and stability of the SMN gene products. Am J Pathol 171:1269-1280.

Wang CC, Jong YJ, Chang JG, Chen YL and Wu SM (2010) Universal fluorescent multiplex PCR and capillary electrophoresis for evaluation of gene conversion between SMN1 and SMN2 in spinal muscular atrophy. Anal Bioanal Chem 397:2375-2383.

Watihayati MS, Fatemeh H, Marini M, Atif AB, Zahiruddin WM, Sasongko TH, Tang TH, Zabidi-Hussin ZA, Nishio H and Zilfalil BA (2009) Combination of SMN2 copy number and NAIP deletion predicts disease severity in spinal muscular atrophy. Brain Dev 31:42-45.

Wirth B (2000) An update of the mutation spectrum of the survival motor neuron gene (SMN1) in autosomal recessive spinal muscular atrophy (SMA). Hum Mutat 15:228-237.

Wirth B, Herz M, Wetter A, Moskau S, Hahnen E, RudnikSchoneborn S, Wienker T and Zerres K (1999) Quantitative analysis of survival motor neuron copies: identification of subtle SMN1 mutations in patients with spinal muscular atrophy, genotype-phenotype correlation, and implications for genetic counseling. Am J Hum Genet 64:1340-1356.

Wirth B, Brichta L, Schrank B, Lochmuller H, Blick S, Baasner A and Heller R (2006) Mildly affected patients with spinal muscular atrophy are partially protected by an increased SMN2 copy number. Hum Genet 119:422-428.

$\mathrm{Xu}$ R, Ogino S, Lip V, Fang H and Wu BL (2003) Comparison of PCR-RFLP with allele-specific PCR in genetic testing for spinal muscular atrophy. Genet Test 7:277-281.

Zapletalova E, Hedvicakova P, Kozak L, Vondracek P, Gaillyova R, Marikova T, Kalina Z, Juttnerova V, Fajkus J and Fajkusova L (2007) Analysis of point mutations in the SMN1 gene in SMA patients bearing a single SMN1 copy. Neuromuscul Disord 17:476-481.

Zerres K and Rudnik-Schoneborn S (1995) Natural history in proximal spinal muscular atrophy. Clinical analysis of 445 patients and suggestions for a modification of existing classifications. Arch Neurol 52:518-523.

License information: This is an open-access article distributed under the terms of the Creative Commons Attribution License, which permits unrestricted use, distribution, and reproduction in any medium, provided the original work is properly cited. 